\title{
Singularidades do trabalho rural: masculinidades e procura por serviços de saúde em um território norte mineiro
}

\author{
I ${ }^{1}$ Sergio Vinicius Cardoso de Miranda, ${ }^{2}$ Pamela Scarlat Duraes Oliveira, \\ ${ }^{3}$ Cristina Andrade Sampaio, ${ }^{4}$ Luiz Carlos Fadel de Vasconcellos I
}

Resumo: Este artigo apresenta um panorama sobre as percepçóes de homens residentes em um território rural do norte de Minas Gerais, Brasil, sobre a sua masculinidade e as interferências do trabalho na procura por serviços de saúde ofertados por uma equipe da estratégia de saúde da família. O método priorizado foi a hermenêutica-dialética com a observação participante, registros em um diário de campo e a realização de 41 entrevistas individuais. A análise dos dados evidenciou que o trabalho rural e o modelo de masculinidade hegemônica direcionam esses homens para o papel de provedor financeiro das famílias. A maioria dos trabalhadores só procura os serviços de atenção primária à saúde quando apresentam condiçóes agudas que interferem na execução do trabalho, considerando a unidade básica de saúde como um espaço feminino. As formas como as masculinidades e os serviços de saúde se colocam nesse território suscitam sentimentos de distanciamento dos trabalhadores rurais das práticas de cuidado em saúde. Um dos grandes desafios é o desenvolvimento de açóes que aproximem esse público da equipe de saúde e vice-versa, contribuindo, assim, para o acesso, o acolhimento e a vinculação dos cuidados à população masculina.

> Palavras-chave: Zona Rural; Trabalho; Masculinidade; Serviços de saúde.

\author{
1 Universidade Estadual de \\ Montes Claros. Montes Claros- \\ MG, Brasil (sergioenfermagem@ \\ yahoo.com.br). \\ ORCID: 0000-0002-8482-7560 \\ ${ }^{2}$ Universidade Estadual de \\ Montes Claros. Montes Claros- \\ MG, Brasil (pamela-scarlatt@bol. \\ com.br). \\ ORCID: 0000-0001-6084-5011 \\ ${ }^{3}$ Universidade Estadual de Montes \\ Claros. Montes Claros-MG, Brasil \\ (cristina.sampaio@unimontes.br). \\ ORCID: 0000-0002-9067-4425 \\ ${ }^{4}$ Escola Nacional de Saúde \\ Pública. Rio de Janeiro-RJ, Brasil \\ (mvasconcellos@uol.com.br). \\ ORCID: 0000-0002-7679-9870
}

Recebido em: 01/06/2018 Aprovado em: 13/01/2020 Revisado em: 19/05/2021 


\section{Introdução}

Na corrente originada da Geografia Política, a origem da discussão do termo território teve como marco, no século XIX, os estudos de Frederico Ratzel. Nesta linha, define-se o território como um espaço de poder demarcado, controlado e governado pela atuação do Estado e de seus cidadãos (HAESBAERT, 2004). Internamente, é relativamente homogêneo, com uma identidade que vai depender da história de sua construção e da apropriação simbólica dos seus diferentes espaços (BARCELLOS, 2008).

Para Santos (2005), o território é o fundamento do trabalho, o lugar da residência, das trocas materiais e espirituais e do exercício da vida. Cada fato é percebido com maior ou menor intensidade de acordo com a organizaçáo socioespacial, cultural, política e econômica das populaçôes que habitam e produzem cada um desses lugares. Na saúde coletiva, essa multiplicidade de territórios modifica a percepção das pessoas sobre as suas formas de viver, trabalhar, adoecer e cuidar da saúde, com destaque para as singularidades do território rural nesse processo.

O território rural deve ser compreendido pelo movimento constante das relaçóes econômicas, sociais e políticas que a população do campo estabelece com a terra, e não simplesmente o oposto ao urbano. Dentre as novas características, há o crescimento das ocupações rurais não-agrícolas, a pluriatividade da sua população, a mecanização do processo produtivo agropecuário e a instalação de infraestrutura social, como energia elétrica, abastecimento de água, educação e serviços de saúde (PONTE, 2004).

Partindo para a discussão do trabalho, Marx (1985) caracteriza-o como uma interação do homem com o mundo natural, sendo a forma pela qual se apropria da natureza a fim de satisfazer suas necessidades. O trabalho é indispensável à sobrevivência humana e fundamental para a organização social, tendo como uma das principais funçóes a produção de valores de uso e de valores de troca no meio rural. No seu território, ao modificar a natureza pelo trabalho, o homem trabalhador rural também é modificado por ela num processo de interação constante entre o trabalho e o ambiente.

No sistema capitalista, existe uma clivagem entre o trabalhador e o seu trabalho, e essa separação coloca-se como condição fundamental para que o homem perca sua humanidade e seja transformado apenas em força de trabalho. O trabalho rural apresenta relaçôes capitalistas de produção, passando a ser marcado pela extensão 
da jornada de trabalho, intensificação do seu ritmo, pagamento por produção, decréscimo real do valor dos alimentos e o descumprimento de direitos trabalhistas (MARX, 1985; LUZ, 2008).

Nesse contexto, o trabalho torna-se um inimigo do homem do campo, que não tem outra opção a não ser submeter-se a um sistema opressivo de produção, pois, mesmo que sinta na pele o fardo dessa sobrecarga, precisa lutar para garantir a sua sobrevivência e a de sua família (LUZ, 2008).

Os trabalhadores rurais realizam suas atividades de forma arriscada e insalubre, em ambientes propiciadores de diversos riscos, como a exposição aos agrotóxicos, acidentes com animais, acidentes com ferramentas, máquinas e implementos, exposição a ruídos e vibraçôes, às radiaçôes solares, às partículas de grãos, a agentes infecciosos e parasitários, entre outros. Esses riscos ocasionam doenças e/ou agravos como envelhecimento precoce, câncer de pele, exaustão por calor, aumento da pressão arterial, síncopes, cãibras, lombalgias, intoxicaçôes, bronquite crônica, asma, pneumonias, câncer de pulmáo, distúrbios do sono e agravos psicossociais. Muitos são os riscos a que os trabalhadores estão sujeitos em decorrência de seu trabalho, que podem ser classificados em: físicos, biológicos, ergonômicos, psicossociais, mecânicos e de acidentes (SILVA et al., 2005; MENEGAT; FONTANA, 2010).

É importante salientar que a percepção de riscos para os trabalhadores rurais está relacionada, entre outros, à negação do perigo: eles reconhecem o risco da atividade, por exemplo, com o manuseio ou aplicação de agrotóxicos, mas não estão cientes dos limites do problema e da necessidade que têm de buscar por atendimentos em saúde nos casos de intoxicação e/ou adoecimento (PERES; ROZEMBERG; LUCCA, 2005; MENEGAT; FONTANA, 2010).

Juntamente com o trabalho, raça e classe social, o gênero desenvolve-se na realidade empírica, como uma categoria histórica que permite a compreensão de como são organizadas as relaçôes sociais e as suas repercussôes nas condiçôes culturais dos homens trabalhadores rurais. Para Connell (1997), há múltiplas masculinidades e, em seu conjunto, pode haver uma que ocupa um lugar de hegemonia, entendida como um modelo a ser seguido pelos homens nas relaçóes de gênero e como uma posição sempre disputada.

Essa masculinidade hegemônica caracteriza-se por uma posição de dominação por parte dos homens na sociedade, tendo como atributos a virilidade, competitividade, a força, a ambição, entre outros (FIGUEIREDO, 2008). O termo Geografia das 
Masculinidades é adotado por Connell e Messerschmidt (2013), considerando uma estrutura analítica que distingue as masculinidades nos níveis local, regional e global, reconhecendo, então, a importância dos territórios para as práticas masculinas.

Para avançar na discussão sobre o trabalho, a masculinidade e a saúde do homem trabalhador rural, devemos problematizar algumas dificuldades que os homens enfrentam em reconhecerem as suas próprias necessidades de saúde, como a manutenção de um pensamento que rejeita a possibilidade de adoecer; a grande invisibilidade pelos serviços de saúde e o afastamento das práticas de saúde ofertadas por equipes da Estratégia Saúde da Família (ESF). De acordo com Figueiredo (2008), alguns homens preferem utilizar outros serviços, como farmácias ou prontossocorros. Nesses lugares, os homens seriam atendidos mais rapidamente, além da questão do horário de funcionamento e da facilidade de acesso.

Vale destacar ainda que, na ótica do homem trabalhador rural, a incapacidade para trabalhar é uma das principais noções subentendidas no tema da doença, sendo o valor do trabalho reafirmado como identidade das pessoas que vivem no meio rural (SILVA et al., 2005). A pobreza, a fome e o desemprego, que podem advir do fato de o trabalhador estar doente, especialmente no caso daqueles que não recebem benefícios sociais instituídos, mostram-lhes, no cotidiano, seu corpo como fonte de subsistência e única estratégia de reprodução física e social. Destaca-se que a negação da doença e a consequente não-busca por atendimento em saúde ocorrem por mais que existam informaçôes disponíveis que lhes mostram os riscos a que estão expostos (RIQUINHO; GERHARDT, 2010).

Este artigo buscou, então, apresentar um panorama sobre as percepçôes de homens residentes em um território rural do norte de Minas Gerais, Brasil, sobre a sua masculinidade e as interferências do trabalho na procura, ou não, por serviços de saúde ofertados por uma equipe de ESF.

\section{Metodologia}

O presente estudo é parte dos resultados de uma dissertação de mestrado em saúde pública, utilizando a metodologia qualitativa, fundamentada na Hermenêutica-dialética. Segundo Gadamer (1999), na hermenêutica ocorre a compreensão dos sentidos pela comunicação entre os seres humanos, tendo, na linguagem, seu núcleo central. Para Habermas (1987), a dialética busca, nos fatos, 
na linguagem, nos símbolos e na cultura, os núcleos obscuros e contraditórios para realizar uma crítica informada sobre eles.

A coleta de dados foi realizada por meio da observação participante, registros em um diário de campo e entrevistas semiestruturadas gravadas, no período de janeiro a julho de 2016. Como critérios de inclusão, foram selecionados homens, trabalhadores rurais, na faixa etária de 18 a 60 anos. A amostra foi composta por 41 homens residentes no território de Nova Minda, zona rural do município de Japonvar, norte do Estado de Minas Gerais.

O município está localizado a $96 \mathrm{~km}$ de Montes Claros, cidade polo da macrorregiáo e a $535 \mathrm{~km}$ da capital Belo Horizonte. A população estimada pelo IBGE (2010) era de aproximadamente 8.298 habitantes, com predominância rural, onde 5.248 pessoas residiam na zona rural $(63,2 \%)$ e 3.050 pessoas, na zona urbana (36,8\%). A cidade teve sua origem em 1975, a partir do estabelecimento de um pequeno comércio, localizado no trevo rodoviário entre a BR-135 e a MG-202.

Seu nome atual foi criado pelo religioso católico, o padre Antônio José, em razão da confluência das rodovias que ligam as cidades de "Ja"nuária, São João da "Pon"te e "Var"zelândia - "Japonvar". A assistência à saúde é desenvolvida por meio da Atenção Primária à Saúde (APS), com o funcionamento de quatro equipes de ESF, sendo uma na zona urbana e três equipes na zona rural, atendendo os territórios de Nova Minda, Ponte do Mangaí e Melancias.

A comunidade de Nova Minda está situada a $22 \mathrm{~km}$ da sede do município, com 1.958 habitantes, sendo considerada o maior distrito do município. A economia baseia-se nas atividades primárias, em pequenas propriedades rurais, com predomínio da agricultura, pecuária e o extrativismo do fruto do pequi. As atividades terciárias concentram-se na sede da comunidade e principalmente na cidade de Japonvar, com o comércio de bens e prestação de serviços, além do grande número de pequenas fabriquetas de biscoitos, onde anualmente, no mês de junho, é realizada a tradicional Festa Nacional do Biscoito.

Os dados foram coletados no próprio local de trabalho e/ou residências dos entrevistados. Por meio da observaçáo participante, os pesquisadores deram importância à expressão e às vivências dos homens, colocando-os como construtores ativos do processo de compreensão dos fenômenos. Foi realizada também uma aproximação com a equipe de ESF do território para conhecer quais açôes de saúde estavam sendo ofertadas. No diário de campo, foram registradas as impressôes 
dos fatos relevantes no comportamento dos homens durante o seu trabalho, nas entrevistas e informaçôes da rotina de trabalho da equipe de saúde da família.

As entrevistas foram gravadas em áudio, tendo duração média de 50 minutos, e, para preservar o anonimato, cada homem recebeu a letra " $\mathrm{H}$ " numerada de acordo com a ordem de realização. O coordenador da pesquisa, possuía vivência com o território, tendo atuado como enfermeiro da equipe de saúde e na gestão municipal como referência técnica de vigilância em saúde do trabalhador, conseguindo, assim, acesso contínuo no território e relação direta com os sujeitos observados.

Para a análise dos dados, foram utilizados dois níveis de interpretação (MINAYO, 2014). Iniciamos com o mapeamento de todas as informaçóes coletadas durante a observação participante, sendo possível detalhar as características sociais, culturais e históricas desses homens trabalhadores rurais e, principalmente, compreender o seu processo de trabalho in loco.

Em seguida, foram organizadas as anotaçôes dos diários de campo sobre a rotina de trabalho da equipe de ESF, os documentos elaborados no mapeamento da observação participante e a transcrição de todas as gravaçôes das entrevistas, constituindo o corpus tecnicamente trabalhado (MINAYO, 2014). Após esta fase, realizamos a leitura horizontal e exaustiva dos textos e a construção das categorias empíricas, além da leitura transversal de cada subconjunto dos dados, por meio do referencial teórico adotado no estudo.

Finalizamos a análise por meio da construção de uma síntese, utilizando as categorias empíricas e as categorias teóricas. Nessa concepção, considerase que as masculinidades e o trabalho rural são socialmente determinados, onde transformações ocorridas em determinado território e momento histórico atuam diretamente no processo saúde-doença e nas práticas de cuidado em saúde.

A análise do material empírico permitiu a construção de três categorias: "As masculinidades e o trabalho rural"; "Os serviços de saúde do território" e "Interferências do trabalho rural para a procura por serviços de saúde".

No estudo, a hermenêutica possibilitou a compreensão dos textos e unidades de sentido relacionadas diretamente às condiçôes da vida cotidiana e à importância do trabalho. A dialética evidenciou as contradiçôes e diferenças no contexto desses homens trabalhadores rurais.

O projeto foi submetido à avaliação e aprovação pelo Comitê de Ética em Pesquisas (CEP) da Escola Nacional de Saúde Pública Sergio Arouca - Fundação Oswaldo Cruz 
(ENSP/FIOCRUZ), por meio do protocolo no: 1.374.183, de 17/12/2015. Todos os entrevistados assinaram um Termo de Consentimento Livre e Esclarecido, após os pesquisadores responderem todas as suas dúvidas, deixando clara a preservação do sigilo das informaçôes e a inexistência de conflitos de interesses.

\section{Resultados e discussão}

Durante a observação participante, foi constatado que, na região em questão, o trabalho rural é desenvolvido em pequenas propriedades e em um período específico do ano, chamado de "chuvoso", nos meses de outubro a março. O processo de produção inicia-se com a seleçáo das sementes e a limpeza da área para o plantio, com a utilização de instrumentais simples, como enxada, foice e machado. Por meio do arado manual, ocorre o preparo da terra, onde as sementes são plantadas em covas abertas pelas enxadas e com o auxílio da máquina "pé de grilo" ou "matraca". São utilizadas formas de produção de alimentos sustentáveis, livres de agrotóxicos. Os principais alimentos produzidos são feijão, milho, mandioca e abóbora. No território pesquisado, a predominância de homens que desenvolvem o trabalho rural foi na faixa etária de 50 a 60 anos (43\%).

Sobre a situação trabalhista, todos os homens eram autônomos e não possuíam vínculo com a previdência social, trabalhando, em média, 44 horas semanais. $\mathrm{Na}$ região, os jovens adultos buscam outras ocupaçôes, migrando para grandes centros urbanos como Montes Claros, Belo Horizonte e São Paulo, ou para o sul de Minas, para a colheita de café. De acordo com Ramalho e Silveira Neto (2012), os homens jovens são sempre a maioria entre os migrantes na rota rural-urbana, onde os trabalhadores rurais dotados de baixa instrução dirigem-se para as grandes cidades à procura de um emprego temporário no setor informal até a fixação no setor formal.

O fato de residir em zona rural, ou seja, morar na propriedade onde trabalha, torna o trabalhador mais propenso a aceitar um vínculo de trabalho não formal. Outra questão levantada pelo Departamento Intersindical de Estatística e Estudos Socioeconômicos-DIEESE (2014) é que a migração e os trabalhos de curta duração (em determinados períodos do ano) também contribuem para o elevado percentual de trabalhadores informais com local de residência em áreas rurais.

Do total de participantes, $63 \%$ relataram uma média salarial de até um saláriomínimo e $65 \%$ declararam possuir o primeiro grau incompleto, sabendo apenas 
assinar seu nome. No contexto do trabalho rural, a escolaridade pouco influencia na ocupação e/ou rendimento do trabalhador, não existindo exigência de nível de escolaridade para desempenhar o trabalho no campo. Ainda de acordo com o DIEESE (2014), baixa escolaridade aliada à situaçâo de informalidade traduz-se, quase sempre, em baixa remuneração.

Em relação ao estado civil, $68 \%$ dos homens pesquisados são casados no civil. Observa-se que o casamento é uma tradição cultural e religiosa do norte de Minas, onde as famílias incentivam fortemente os filhos para o casamento e a constituição de novos núcleos familiares. Os homens que são casados também são mais respeitados no território pesquisado. Outro dado que chamou a atenção foi que apenas um homem informou ser viúvo, sendo um agravante para a saúde dos trabalhadores rurais locais.

As categorias empíricas são discutidas a seguir.

\section{As masculinidades e o trabalho rural}

$\mathrm{Na}$ compreensão do território rural, há de se considerar a terra e o trabalho como principais fatores de estabelecimento dos tipos de relaçôes sociais, econômicas e políticas da população do campo. Nessas relações, há o predomínio de dimensôes simbólicas e culturais, que influenciam os comportamentos considerados típicos ou necessários para as condutas masculinas.

Por meio das entrevistas realizadas, foi possível compreender como esses homens percebem a questão da identidade de gênero e as marcas da identidade masculina, onde "ser homem" está diretamente relacionado à força, à honestidade e à responsabilidade:

\footnotetext{
"Para ser homem tem que primeiro ser forte. O homem tem que honrar a palavra dele e se for preciso brigar pelos seus direitos [...] ele tem que brigar" (H2).

"O homem é honesto. Todo mundo admira: aquele ali é homem! Cumpre todas as suas obrigaçôes dentro e fora de casa" (H16).
}

Nesse sentido, o gênero deve ser contextualizado pela proximidade do mundo social e cultural no qual os indivíduos estão inseridos. A socialização na zona rural ocorre por meio dos pais, da escola, das igrejas, da comunidade e, a partir dos anos 2000, pelas mídias. Em muitas culturas, as características básicas da masculinidade incluem capacidades físicas, coragem, maestria, honra e liderança (FIGUEIREDO, 2008). 
Segundo Connell (1997), no modelo da masculinidade hegemônica, ser homem representa por si só um empoderamento social. A questão do exercício de um papel social e comunitário pelo homem trabalhador rural foi observada no presente estudo: "[...] A gente tem que ter bastante amizade, ser conhecido por todos na comunidade. $\mathrm{O}$ homem aqui é amigo de todo mundo. É uma liderança local. Acho importante o homem ser respeitado pelo que é" (H5).

Nas sociedades ocidentais, o trabalho tem sido considerado atributo essencial para o desenvolvimento da identidade masculina. Desde a infância, os meninos são induzidos ao distanciamento da figura materna e do universo doméstico, principalmente no sentido de alcançar o ambiente externo e a capacidade de trabalhar (REIS; COSTA, 2014).

Ao considerar o meio e as práticas de ação do cotidiano de trabalhadores rurais, compreendem-se a importância e a subjetivação que o fazer, por meio da realização do trabalho, possibilita a cada um. Nesse sentido, o ato de náo trabalhar ou ficar sem exercer algum tipo de ocupação, seja por doença ou não, é expresso como um atraso. Ainda que seja concedido algum benefício financeiro para suprir as necessidades vitais nessas situaçôes, seu ganho não é prazeroso, pois não provém do trabalho direto (RIQUINHO; GERHARDT, 2010).

"O trabalho na roça é a profissão do homem daqui [...] e ao mesmo tempo uma tradição, porque vem de família 'né. Meu pai que me ensinou mexer com a terra" (H24).

A existência de trabalho cria a condição essencial para a saúde e qualidade de vida. O trabalho é considerado prazeroso pelo homem porque lidar com a terra não é só garantia de sustento, mas também a liberdade para decidir sobre quando e como trabalhar, podendo evitar o contato com certos tipos de riscos. O trabalho no ambiente rural envolve movimentos do corpo, convivência social e despreocupação com cargas horárias e com regras rígidas (MENEGAT; FONTANA, 2010).

O modelo masculino de trabalhador proposto por Hassard, Hollyday e Willmot (2000) destaca que o corpo próprio para o trabalho foi concebido pelo ideal de corpo masculino, disciplinado, emocionalmente controlado e sempre disponível para a produção, o que fica evidenciado no trabalhador rural conforme a fala de um entrevistado:

"O que a gente faz no trabalho exige muito do nosso corpo e da força do homem. Trabalhar na roça é pegar no pesado [...] nosso corpo já 'tá preparado para isso" (H15). 
As noçóes de masculinidade compartilhadas neste território misturam-se com a concepção do trabalho rural, enraizado em aspectos regionais que reforçam as formas de ser e agir desses homens. Conforme Lukács (1981), a gênese do trabalho produzida e reproduzida é uma construção complexa da essência humana, principalmente dos homens, sendo considerada o início da autoconstituição da humanidade enquanto gênero.

De acordo com o estudo de Reis e Costa (2014), a questáo do ingresso no mercado de trabalho representa para o homem uma forma de exercício da masculinidade propriamente dita, por meio do afastamento da família pelo alcance da sua independência financeira.

"O homem tem que trabalhar fora de casa, na roça. Produzir muito para ser independente e ter como pagar todas as suas contas [...]" (H19).

A partir dessa independência, nasce a possibilidade da constituição de uma nova família e o exercício do papel do homem de provedor. Na medida em que trabalham e geram recursos materiais capazes de garantir o sustento familiar, os homens obtêm reconhecimento de sua posição por outros homens, que passam a reconhecer seu status no grupo. Nessa ideologia de pensamento, o domínio das mulheres do campo é apenas o espaço doméstico e o de dona de casa, a responsável por cuidar dos filhos e gerir a economia doméstica (HASSARD; HOLLYDAY; WILLMOT, 2000).

\footnotetext{
"A mulher aqui fica em casa cuidando de tudo. Nós é que temos que trabalhar para sustentar a família. Colocar tudo dentro de casa [...] porque a roça náo é lugar de mulher não" (H12).
}

De acordo com Connell e Messerschmidt (2013), existe uma geografia das masculinidades com especificidades locais, regionais e globais. O nível local é construído por meio da interação face a face dos indivíduos, famílias, organizações e comunidades; o regional, pela integração de práticas locais específicas em determinada macrorregião e o nível global, pelas arenas transnacionais das políticas mundiais e da mídia. Ao se adotar essa estrutura analítica que distingue esses três níveis, reconhecemos e valorizamos a importância de cada território para a formação das diferentes masculinidades.

Nessa perspectiva, estudos mundiais sobre a condição masculina e sobre os homens passaram a tratar não da masculinidade no singular, mas de "masculinidades", no plural. Falar em masculinidade no singular sugere a ideia 
de uma representação homogênea e, ao se colocar a noção de masculinidades, no plural, deduz-se que existem outros tipos de masculinidade (CONNELL, 1997). Foi possível detectar, nas falas de alguns homens, elementos para se pensar em novas possibilidades de masculinidades:

\footnotetext{
"Ser homem não é só ser valente, casado ou trabalhar. É muito mais que isso [...] tem outras coisas que faz a gente ser homem de verdade" (H3).

"O homem não é mais importante que é a mulher. Isso tem mudado muito [...] Os direitos e deveres dos homens e das mulheres são iguais uai! Os dois são trabalhadores e honestos" (H31).
}

Os discursos desses homens projetam elementos importantes para o entendimento da construção e desenvolvimento "das" suas masculinidades, considerando a grande influência do nível local - o município de Japonvar - e do nível regional - o norte de Minas. Apesar de os modelos de masculinidade poderem se diferenciar uns dos outros, eles geralmente se sobrepõem no nível global. Nesse sentido, Kaufman (1995, p. 125) destaca que:

"[...] as formas de masculinidade baseiam-se no poder social dos homens, mas são assumidas de modo complexo por homens individuais que também desenvolvem relaçóes harmoniosas com outras masculinidades".

\section{Os serviços de saúde do território}

O debate em torno do processo de trabalho de equipes de saúde da família tem-se mostrado extremamente importante para a compreensão da organização da assistência à saúde em determinados territórios e comunidades, fundamentalmente, pela sua potência transformadora em prol da promoção da saúde por meio da micropolítica da organização do trabalho multiprofissional e das práticas de cuidado em saúde (FRANCO; MERHY, 2007).

A comunidade de Nova Minda possui implantada, desde 2010, uma equipe da Estratégia de Saúde da Família e de Saúde Bucal, denominada como "Estratégia Saúde da Família Felicidade", com o código no 2172534, no Cadastro Nacional dos Estabelecimentos de Saúde. A equipe atende exclusivamente à população rural, tendo, na sua composição, um médico, um enfermeiro, três técnicos de enfermagem, cinco Agentes Comunitários de Saúde (ACS), um cirurgião dentista e um técnico de saúde bucal. 
Os atendimentos são realizados em duas Unidades ESF: ESF sede na comunidade de Nova Minda e uma ESF ponto de apoio na fazenda Dois Barreiros. No período da pesquisa, estavam cadastradas na equipe 547 famílias, totalizando 1.958 habitantes (100\% de cobertura), sendo representados por 997 homens e 961 mulheres. Esse quantitativo é atualizado mensalmente pelos ACS no e-SUS, que é o principal banco de dados do Sistema de Informação em Saúde para a Atenção Básica do Ministério da Saúde.

As ações programáticas ofertadas estão ligadas principalmente às áreas de saúde da mulher e saúde da criança, além da saúde do adulto, saúde do idoso e saúde mental. Realizam-se consultas médicas; consultas de enfermagem; prevenção do câncer de colo uterino e de mama; planejamento familiar; pré-natal; puericultura e avaliação do crescimento e desenvolvimento infantil; atenção aos hipertensos e diabéticos; renovação de receitas de controle e atendimentos odontológicos.

As visitas domiciliares são realizadas por todos os profissionais da equipe de acordo com a demanda dos problemas apresentados pelos moradores. A equipe conta com um veículo da secretaria municipal de saúde para o acompanhamento domiciliar pelos profissionais de nível superior, que é utilizado também para o transporte desses profissionais da sede do município até a zona rural. Os ACS realizam suas visitas a pé ou em motos particulares, devido às longas distâncias geográficas da zona rural.

$\mathrm{O}$ médico, o enfermeiro e o dentista atendem no território de segunda à sextafeira (exceto nos feriados), de 7:00 às 14:00 horas. Essa modalidade de horário é muito utilizada por equipes de saúde da família rurais, sendo conhecida como "horário corrido". Para a equipe, esse horário permite uma maior agilidade nos atendimentos e deslocamentos. A programação da agenda mensal contempla: segundas e quartas-feiras, a ESF de Nova Minda; terças-feiras, a ESF de Dois Barreiros; quintas-feiras, atendimento móvel em pequenas fazendas; e às sextasfeiras, são realizadas as visitas domiciliares, além dos grupos de educação em saúde e reuniôes administrativas da equipe.

O Ministério da Saúde (2017), por meio da Política Nacional da Atenção Básica, coloca que sáo características do processo de trabalho das equipes de ESF: a programação e implementação de atividades de acordo com as necessidades de saúde da população do território adscrito, com a priorização de intervençôes clínicas e sanitárias nos problemas de saúde segundo critérios de frequência, risco, 
vulnerabilidade e resiliência. Incluem-se, também, o planejamento e a organização de uma agenda de trabalho compartilhada entre todos os profissionais.

Ao analisar como estão organizadas as açóes de saúde nesse território, surgiu, então, uma grande inquietude: onde estão presentes, no processo de trabalho da equipe, açôes específicas voltadas para a saúde do homem e para a saúde do trabalhador rural? Essa análise é fundamental para se (re)pensar como os modelos assistenciais são implantados e reproduzidos pelo Estado em territórios rurais. Esse modelo designado biomédico tem influenciado a formação profissional, a organização dos serviços e as práticas de cuidado em saúde.

Considerando que os homens apresentam menos iniciativas voluntárias de se consultarem periodicamente e aderem pouco aos tratamentos preconizados ou orientações de promoção e prevenção, é de se esperar que esse público acabe perfazendo um grupo de atendimento com baixa adesão, no qual doenças e complicaçóes terminam por levá-los a quadros mais graves e crônicos. Também por esse processo, tem-se, dentre a população masculina, alguns indicadores de saúde preocupantes, tais como para alcoolismo e tabagismo, a violência e dados de morbimortalidade (SCHRAIBER et al., 2010).

Junto a essa discussão, partilhamos da ideia de que os homens costumam ser invisibilizados nos serviços de saúde. Couto et al. (2010) observaram que essa invisibilidade favorece o ocultamento das demandas e necessidades masculinas, numa perspectiva de gênero, por parte da dos serviços da APS. No geral, essas equipes de saúde não têm como rotina a oferta de açôes para a população masculina (GOMES; NASCIMENTO; ARAUJO, 2007).

\section{Interferências do trabalho rural para a procura por serviços de saúde}

$\mathrm{O}$ trabalho rural engloba tanto o empregado rural como aquele que se dedica, por conta própria, ao labor rural, seja como arrendatário, parceiro, meeiro ou em sua própria propriedade. É o modo de produzir e fazer agricultura, sendo desenvolvido de tal maneira que não se diferencia o universo dos que decidem sobre o processo de produção e dos que se apropriam do resultado desse trabalho, estando diretamente relacionado ao modo de viver das famílias do campo (NASCIMENTO, 2007).

Nesse modo de vida e trabalho, são estabelecidos valores e práticas que são transmitidos pelas relaçôes familiares, vizinhos e comunidade. No território, é utilizada a técnica do agrossistema tradicional, com a baixa utilização de recursos 
tecnológicos para o plantio e cultivo. Devido à pouca quantidade de solos férteis, a maioria das lavouras é temporária, visando, principalmente, ao autoconsumo de milho, feijão, mandioca e cana-de-açúcar. A produção pecuária de leite também é expressiva, com a fabricação de queijos e requeijão.

Na obra "Trabalho Assalariado e Capital", Marx (1990) coloca que, no processo de produção, os homens não agem apenas sobre a natureza, mas também agem uns sobre os outros e, para produzirem, contraem determinados vínculos e relaçôes mútuas. Os discursos dos homens pesquisados apontam que a principal interferência para a procura por serviços de saúde da família está diretamente ligada ao trabalho rural:

\footnotetext{
"Se eu ficar um dia sem olhar a lavoura o mato cresce e os bichos comem tudo que plantei. Não tem como 'tá faltando o trabalho [...] aí não sobra tempo para a gente 'tá indo no posto de saúde" (H8).
}

Gomes, Nascimento e Araujo (2007) observaram, em quatro estados brasileiros, uma menor procura, por parte dos homens, por serviços de saúde em unidades de saúde da família. As atividades produtivas viriam em primeiro lugar na lista de preocupaçôes e as ausências estiveram diretamente ligadas ao desempenho do trabalho, onde a busca por esses serviços ficaria em segundo plano. Nesse estudo, os homens relataram que, ao procurarem a ESF para uma consulta, enfrentavam filas, que levariam a perder o dia de trabalho e sem necessariamente terem suas demandas resolvidas em um único atendimento.

De acordo com estudo qualitativo realizado por Couto et al. (2010), o trabalho apareceu também como a principal referência para os homens entrevistados, sendo considerado prioritário inclusive em relaçáo ao cuidado à saúde. Foram expressas situaçôes como a preocupação com o sustento da família e a responsabilidade relacionada ao trabalho, sobretudo no caso dos autônomos, que impediriam a procura por serviços de saúde, assim como observamos nesta pesquisa:

"Já ganho muito pouco [...] se faltar um dia de trabalho as coisas pioram muito. O que ganho é por dia. Se não produzir todo dia a gente passa necessidade" (H37).

O trabalho, nesse contexto, impede a procura por serviços de saúde. $\mathrm{Na}$ concepção de Marx (1990), o homem não pode viver sem produzir seus meios de subsistência, e só pode produzi-los na medida em que trabalha. A fala do indivíduo acima evidencia a importância do trabalho na vida do homem do campo, e destaca que a doença está diretamente relacionada à incapacidade para trabalhar 
e, consequentemente, à possibilidade de viver em situação de pobreza devido à baixa produtividade. Grande parte desses homens não recebe benefícios sociais instituídos, sendo que o sustento de sua família vem da sua força de trabalho, do seu corpo (SILVA et al., 2005; RIQUINHO; GERHARDT, 2010).

A possibilidade de não conseguir progresso nas questôes relativas às suas ocupaçóes, o acúmulo de muitas tarefas no trabalho ou a possibilidade da perda do emprego podem gerar tensôes não somente econômicas, mas também de identidade e de saúde. Na pesquisa de Silva et al. (2012) e no presente estudo muitos homens priorizaram suas tarefas em detrimento do cuidado à saúde.

"Ah... eu não gosto de ficar indo lá no 'PSF não. Homem não tem essas coisas de ficar consultando por qualquer bobagem" (H2).

Outra questão observada foi o horário de funcionamento da equipe de ESF. Como a equipe adota a modalidade de horário "corrido", o médico, o enfermeiro e o dentista só realizam os atendimentos até as 14:00 horas. Nos discursos dos homens trabalhadores rurais, esse horário não atenderia às suas demandas, por coincidir exatamente com o horário de seu trabalho. Ainda de acordo com Silva et al. (2012), outro fator impeditivo da procura dos homens pelos serviços de saúde refere-se à dificuldade de encontrar unidades abertas após as 17 horas.

"O melhor horário para trabalhar na roça é de manhã. O sol 'tá mais frio [...] mais fresquinho. E é bem o horário que o posto de saúde funciona" (H26).

"O médico só vem aqui na hora que estamos trabalhando [...] então não tem como os homens que trabalham consultar [...] resolver seus problemas 'né [...]" (H40).

O horário de funcionamento dos serviços de saúde pública constitui-se, assim, como uma barreira institucional importante para os homens. Esse horário é incompatível com a disponibilidade da população masculina, residente na zona urbana ou rural e inserida no mercado formal e informal de trabalho. Observa-se, ainda, que esse problema não se reduz apenas aos homens, pois o horário de funcionamento dessas instituiçôes nem sempre é conciliável com os horários de trabalho, independentemente do gênero e do tipo de ocupação (GOMES; NASCIMENTO; ARAUJO, 2007).

Outra explicação dos homens trabalhadores rurais para a não procura pelos serviços de saúde refere aos dias de funcionamento da equipe de saúde da família, que nem sempre são conciliáveis com os seus dias de trabalho (SILVA et al., 2012; FIGUEIREDO, 2008). 


\begin{abstract}
"O dia que a gente folga é domingo [...] sábado trabalho até meio dia. O problema de consultar domingo é que tem que ir lá na cidade [...] e isso fica mais complicado pela distância" (H41).

"Durante a semana 'tô trabalhando. Tenho que plantar muito para poder colher bastante. Só sábado e domingo que tenho tempo para consultar [...] Ou entâo quando 'tô sentido alguma coisa que pode atrapalhar de ir trabalhar 'né" (H4).
\end{abstract}

Os dias de funcionamento da equipe de ESF observada não atende às demandas dos homens trabalhadores rurais, coincidindo com os dias úteis de trabalho no campo.

"Só falto o meu serviço para consultar se tiver sentindo algo grave. Senão como vou poder trabalhar? Aí tem que consultar [...] não tem jeito" (H11).

De acordo com Figueiredo (2008), é maior a prevalência masculina na procura de serviços emergenciais, como hospitais e prontos-socorros, além das farmácias. Esses locais responderiam mais objetivamente às suas demandas, com um atendimento mais rápido e a facilidade de expor seus problemas de saúde em qualquer dia e horário.

Os estudos de Gomes, Nascimento e Araujo (2007) e Couto et al. (2010) evidenciaram ainda que, nos serviços da APS nos quais foram disponibilizados atendimento no horário do almoço, atendimento 24 horas, aos sábados e domingos ou que criaram um terceiro turno à noite, houve uma maior presença masculina nessas novas configuraçóes ampliadas de atendimento.

\title{
Consideraçóes Finais
}

O modelo de masculinidade hegemônica é predominante na cultura norte mineira, e localmente determina que os homens assumam o papel de provedor financeiro das famílias, além de terem que ocupar um espaço importante na sociedade produtiva.

O trabalho rural ocupa uma centralidade no que diz respeito à identidade masculina, sendo desenvolvido pelos homens em suas pequenas propriedades ou de vizinhos e tendo como principais atividades o cultivo da terra, com o preparo para a plantação, a semeadura dos alimentos e o cuidado permanente da "roça". No final desse processo, é realizada a colheita do que foi produzido, garantindo, assim, a sobrevivência das famílias por meio do autoconsumo.

As formas como as masculinidades e os serviços de saúde se colocam nesse território suscitam sentimentos de distanciamento dos trabalhadores rurais das práticas de cuidado em saúde. Sobre a procura por açôes de saúde da família, observamos que os horários e dias de funcionamento da equipe de ESF do território 
não atende às demandas dos homens trabalhadores rurais, principalmente por coincidir com o horário do seu trabalho.

A maioria dos trabalhadores só procura os serviços de APS quando apresentam condições agudas que interferem na execução do trabalho, considerando a unidade básica de saúde como um espaço feminino. Constatamos que a equipe de saúde desenvolve açôes quase que exclusivas para a saúde das mulheres e das crianças, o que acaba reforçando esse pensamento masculino.

Apesar de inegáveis avanços obtidos no Sistema Único de Saúde com a implantação da ESF, seus princípios orientadores ainda não são uma realidade no cotidiano da maioria dos serviços de saúde, e na zona rural, muito menos. No Brasil, alguns espaços de gestão e de atenção ainda não consideram a saúde como um fenômeno indissociável do desenvolvimento econômico e social.

Para que a discussão sobre a saúde da família no campo não seja realizada apenas em uma perspectiva utópica, temos que ter em mente que as limitações e dificuldades para os seus avanços existem. Um dos grandes desafios é o desenvolvimento de ações que aproximem o homem trabalhador rural da equipe de saúde e vice-versa, contribuindo, assim, para o acesso, o acolhimento e a vinculação dos cuidados à população masculina.

\section{Agradecimentos}

Agradecemos ao Ministério da Saúde, por meio do Departamento de Apoio à Gestão Participativa (DAGEP/SGEP), pela concessão de bolsa de mestrado do primeiro autor, à Secretaria Municipal de Saúde de Japonvar pela liberação do profissional e aos homens pesquisados pelos encontros e diálogos.

\section{Referências}

BARCELLOS, C. (Org.). Território, Ambiente e Saúde. Rio de Janeiro: Editora Fiocruz, 2008.

BRASIL. Ministério da Saúde. Portaria no 2.436 de 21 de setembro de 2017. Aprova a Nova Política Nacional de Atenção Básica, estabelecendo a revisão de diretrizes para a organização da Atenção Básica, no âmbito do Sistema Único de Saúde (SUS). Brasília, DF: Ministério da Saúde, 2017.

CONNELL, R.; MESSERSCHMIDT, J. Masculinidade hegemônica: repensando o conceito. Rev. Estudos Feministas, CFH/CCE/UFSC, v. 21, n. 1, p. 241-242, 2013. 
CONNELL, R.W. La organización social de la masculinidad. In: VALDES, T.; OLAVARIA, J. (Edit). Masculinidad: poder y crisis. Santiago do Chile: Ediciones de las Mujeres; 1997.

COUTO, M.T. et al. O homem na atenção primária à saúde: discutindo (in)visibilidade a partir da perspectiva de gênero. Rev. Interface (Botucatu), São Paulo, v. 14, n. 33, p. 257-70, 2010.

DIEESE. Departamento Intersindical de Estatística e Estudos Socioeconômicos. O mercado de trabalho assalariado rural brasileiro. São Paulo; 2014. Disponível em: http://www.dieese.org.br/ estudosepesquisas/2014/estpesq74trabalhoRural.pdf. Acesso em: 12 abr. 2016.

FIGUEIREDO, W.S. Masculinidades e Cuidado: diversidade e necessidades de saúde dos homens na atenção primária. Tese (Doutorado em Ciências - Medicina Preventiva). Faculdade de Medicina da Universidade de São Paulo, São Paulo, 2008. 295 f.

FRANCO, T.B.; MERHY, E.L. Programa de Saúde da Família (PSF): contradiçôes de um programa destinado à mudança do modelo tecnoassistencial. In: O trabalho em saúde: olhando e experienciando o SUS no cotidiano. São Paulo: HUCITEC, 2007.

GADAMER, H.G. Verdade e Método. 3. ed. Petrópolis: Editora Vozes, 1999.

GOMES, R.; NASCIMENTO, E.F.; ARAUJO, F.C. Por que os homens buscam menos os serviços de saúde do que as mulheres? As explicaçóes de homens com baixa escolaridade e homens com ensino superior. Rev. Cad. Saúde Pública, Rio de Janeiro, v. 23, n. 3, p. 565-574, 2007.

HABERMAS, J. Conhecimento e interesse. Rio de Janeiro: Guanabara, 1987.

HAESBAERT, R. Dos múltiplos territórios à multiterritorialidade. Porto Alegre, 2004. Disponível em: <http://www.msh.univse2.fr/cdp/documents/CONFERENCE\%20 Rogerio\%haesbaert.pdf> Acesso em: 16 mai. 2016.

HASSARD, J.; HOLLYDAY, R.; WILLMOT, H. Introduction: the body and organization. In: Bodies and organization. London, Thousand Oaks; New Delhi: Sage Publications, 2000.

IBGE. Instituto Brasileiro de Geografia e Estatística. Censo Demográfico 2010. Disponível em: <http://www.censo2010.ibge.gov.br>. Acesso em: 18 de mar. 2016.

KAUFMAN, M. Los Hombres, el feminismo y las experiencias contradictorias del poder entre los hombres. In: ARANGO, L. G., LEÓN, M., VIVEROS, M. (Comp.). Género e identidad. Ensayos sobre lo feminino y lo masculino. Bogotá: T. M./ Uniandes/ UN. 1995.

LUKÁCS, G. Per una ontologia dell'essere sociale. Roma: Riuniti, 1981.

LUZ, R.S. Trabalho alienado em Marx: a base do Capitalismo. Dissertação (Mestrado em Filosofia). Universidade Católica do Rio Grande do Sul, Porto Alegre, 2008, $101 \mathrm{f}$.

MARX, K. Lohnarbeit und Kapital. In: Marx/Engels, Werke (MEGA). Dietz Verlag, Berlin, 1990. MARX, K. O Capital: crítica da economia política. São Paulo: Abril Cultural, 1985. 
MENEGAT, R.P.; FONTANA, R.T. Condiçôes de trabalho do trabalhador rural e sua interface com o risco de adoecimento. Rev. Ciênc. Cuid. Saúde, v. 9, n. 1, p. 52-59, 2010.

MINAYO, M.C.S. O desafio do conhecimento: Pesquisa qualitativa em saúde. 14. ed. São Paulo: Ed. Hucitec, 2014.

NASCIMENTO, A.M. Iniciação do direito do trabalho. São Paulo: LTr. 2007.

PERES, F.; ROZEMBERG, B.; LUCCA, S.R. Percepção de riscos relacionada ao trabalho rural em uma região agrícola do estado do Rio de Janeiro, Brasil: agrotóxicos, saúde e ambiente. Rev. Cad. Saúde Pública, Rio de Janeiro, v. 21, n. 6, p. 1836-1844, 2005.

PONTE, K.F. (Re) Pensando o Conceito do Rural. Rev. Nera, São Paulo, n. 4, V. 7, p. 20-28, 2004.

RAMALHO, H.M.B.; SILVEIRA NETO, R.M. A Inserção do migrante rural no mercado de trabalho urbano no Brasil: uma análise empírica da importância dos setores informal e formal. Rev. Estud. Econ., v. 42, n. 4, p. 731-771, 2012.

REIS, S.S.; COSTA, M.M.M. Trabalho, educação e gênero: desafios e perspectivas da inserção da mulher no mercado de trabalho no século XXI. Curitiba: Multideia, 2014.

RIQUINHO, D.L.; GERHARDT, T.E. A transitoriedade nos estados de saúde e doença: construçáo do cotidiano individual e coletivo em uma comunidade rural. Rev. Trab. educ. saúde, Rio de Janeiro, v. 8, n. 3, p. 419-437, 2010.

SANTOS, M. Da totalidade ao lugar. São Paulo: Edusp, 2005.

SCHRAIBER, L.B. et al. Necessidades de saúde e masculinidades: atenção primária no cuidado aos homens. Rev. Cad. Saúde Pública, Rio de Janeiro, v. 26, n. 5, p. 961-970, 2010.

SILVA, J.M. et al. Agrotóxico e trabalho: uma combinação perigosa para a saúde do trabalhador rural. Rev. Ciênc. Saúde Coletiva, Rio de Janeiro, v. 10, n. 4, p. 891-903, 2005.

SILVA, P.A.S. et al. Saúde do homem na visão do enfermeiro. Rev. Escola Anna Nery, v. 16, n. 3, p. 561-568, 2012. 


\section{Abstract}

Singularities of rural work: masculinities and demand for health services in a territory in north Minas Gerais

This article presents an overview of the perceptions of men living in a rural territory of northern Minas Gerais, Brazil, about their masculinity and the interferences of work in the search for health services offered by a family health strategy team. The method prioritized was hermeneutics-dialectics with participant observation, records in a field diary and 41 individual interviews. Data analysis showed that rural work and the hegemonic masculinity model direct these men to the role of financial provider of families. Most workers only seek primary health care services when they present acute conditions that interfere in the execution of work, considering the basic health unit as a female space. The ways in which masculinities and health services are placed in this territory give rise to feelings of distancing rural workers from health care practices. One of the major challenges is the development of actions that bring this public closer to the health team and vice versa, thus contributing to access, reception and linking care to the male population.

> Keywords: Rural Zone. Work. Masculinity. Health Services. 